\title{
Impaired uterine artery flow associated with the presence of ovarian endometrioma: preliminary results of a prospective study
}

\author{
Maria Grazia Porpora ${ }^{1 *}$, Federica Tomao', Lucia Manganaro², Deliar Yazdanian ${ }^{1}$, Eliana Fuggetta1, \\ Maria Grazia Piccioni ${ }^{1}$, Pierluigi Benedetti Panici ${ }^{1}$ and Giuseppe Benagiano ${ }^{1}$
}

\begin{abstract}
Background: Aim of this prospective, case-control study was to evaluate uterine arteries' blood flow before and after laparoscopic surgery in patients with ovarian endometriosis and its possible correlation with infertility.

Methods: We prospectively enrolled 110 women of reproductive age; 69 with ovarian endometriomas and scheduled for surgery, and 41 controls. At enrolment, a detailed medical, gynecologic and obstetric history was collected. Fertility and pregnancy desire were assessed. All patients underwent complete physical and gynecologic examination. Transvaginal ultrasound with Doppler color flow was performed to evaluate Resistance Index (RI) of uterine arteries during the secretory phase, at enrolment (TO) and 3 months after laparoscopic surgery (T1).

Results: Among cases, 27 patients were excluded because they did not meet the inclusion criteria. At enrolment (TO) unilateral or bilateral flow alterations $(R I \geq 0.8)$ were found in 38 out of 42 patients with ovarian endometriosis (90\%), whereas in the control group only 17 women (41\%) had Doppler alterations. The difference in uterine artery $\mathrm{RI}$ values between cases and controls was statistically significant $(P<0.0001)$. A statistically significant improvement in uterine artery flow $(P<0.0001)$ was found 3 months after surgical treatment of endometriosis. Nineteen patients with endometriosis (45\%) were infertile before surgery; all of them presented uterine artery Doppler alterations at T0. After surgery the pregnancy rate was significantly higher in patients who presented uterine artery flow normalization than in those with persistent uterine artery flow alterations $(p=0.002)$.
\end{abstract}

Conclusions: A strong correlation was found between uterine artery flow abnormalities and ovarian endometriosis. Uterine artery flow improvement following surgery seems to increase the probabilities of achieving pregnancy.

Keywords: Color doppler, Endometriosis, Infertility, Ultrasounds, Uterine artery flow, Resistance Index (RI)

\section{Background}

The presence of endometriosis induces a chronic inflammatory condition capable of influencing pregnancy outcome [1] and, although the condition can be asymptomatic, according to a recent statement by the American Society for Reproductive Medicine "typically presents with pelvic pain, infertility, or an adnexal mass, and may require surgery" [2]. The prevalence of endometriosis in women undergoing laparoscopy for evaluation of infertility has

\footnotetext{
*Correspondence: mariagrazia.porpora@uniroma1.it

'Department of Gynecology, Obstetrics and Urology, Sapienza, University of Rome, Policlinico Umberto I, Viale Regina Elena 324, Rome 00161, Italy Full list of author information is available at the end of the article
}

been estimated between 9 and $50 \%$ and its presence is 6 to 8 times more frequent in infertile women [3].

A causal relationship between endometriosis and infertility has not been definitely established. In fact while in advanced stages the presence of adhesions and distorted pelvic anatomy may be sufficient to impair fertility, in earlier stages the relationship between endometriosis and subfertility is still a controversial issue. Modifications in the peritoneal fluid and pelvic inflammation may affect fertility and both oocyte and embryo quality. Moreover, eutopic endometrium is altered in women with endometriosis and possibly less receptive due to a well-documented local production of estradiol, coupled with a certain degree of progesterone resistance [4-6]. 
According to prospective cohort studies in infertile women with moderate and severe endometriosis, following laparoscopic removal of lesions and adhesiolysis, the crude spontaneous pregnancy rate ranges between 52 and 69\% [7-9].

In the presence of an ovarian endometrioma additional specific factors may play a role: first of all, there is evidence that cystectomy may decrease the size of the follicle pool [10]; in addition, in these patients the agedependent physiologic decline in the number of ovarian follicles can begin earlier in life [4] and, indeed, the presence of an endometrioma reduces ovarian reserve and decreases the number of oocytes retrieved [11,12]. In vitro fertilization (IVF) followed by embryo transfer (ET) has been extensively utilized to restore fertility in patients with endometriosis [13]. Unfortunately, there is an adverse effect of endometriosis on ovulation rates, ovarian reserve, and response to ovarian stimulation [14]. This effect has been attributed to the disease itself [11], although opinions on this point differ [15-17].

The work of Steer et al. [15] added a new dimension to the search for pathogenetic mechanisms of infertility, when they found cyclic variations in the uterine and ovarian artery blood flow throughout the menstrual cycle [15]. Steer et al. [16] then proposed that deviation from these physiologic changes might reduce fertility, since increased flow resistance in the uterine artery during the midluteal phase was found to be associated with unexplained infertility [16]. Recently El-Mazny et al. confirmed that uterine artery flow parameters were significantly altered in infertile patients, concluding that Doppler study of uterine hemodynamics should be considered in infertility work-up [18].

There are no studies in the literature evaluating uterine artery blood flow alterations in patients with endometriosis.

To explore this new field, a study was set-up to evaluate the presence of uterine artery blood flow alterations in women with ovarian endometriomas, its hypothetical normalization after surgery and a possible influence on reproductive outcome.

\section{Methods}

One-hundred-ten women of reproductive age were enrolled in this prospective, case-control study: 69 consecutive patients with ovarian endometriomas who were scheduled for laparoscopic surgery and 41 controls selected among women undergoing routine check-up.

Patients were recruited among women referred to the Endometriosis and Chronic Pelvic Pain Center of the Department of Gynecology, Obstetrics and Urology of Sapienza, University of Rome, with a suspected diagnosis of ovarian endometrioma. From January 2012 to January 2013, a total of 69 patients with an ultrasound-determined diagnosis were recruited. Women who did not present with clinical and ultrasonographic signs of endometriosis, adenomyosis, history of infertility, uterine malformations and/or other ovarian pathologies and not taking any hormonal therapy, acted as controls; they were selected according to age-matched criteria.

The study protocol was approved by the Institutional Review Board of the University Hospital Azienda Policlinico Umberto I. Written informed consent was obtained from all patients and controls. Patients with endometriomas were enrolled in the study according to the following inclusion criteria:

1) Presence of an ultrasound (US) diagnosis of ovarian endometrioma(s) $\geq 4 \mathrm{~cm}$.

2) Scheduled laparoscopy.

3) Age 18-45 years.

The exclusion criteria were: current hormonal treatment, presence of uterine fibroids, imaging signs of adenomyosis, gynecologic malformations, autoimmune disorders, chronic diseases, coagulation disorders, previous surgery for endometriosis, history of gynecologic surgery or pelvic inflammatory disease. Twenty-seven of the 69 patients were excluded because they did not meet these criteria.

The US diagnosis of ovarian endometrioma was made in the presence of the following preset criteria: a unilocular mass with ground glass echogenicity and a color score between 1 and 3; or a unilocular mass with ground glass echogenicity and a papillary projection, a color score of 1 or 2 and no flow inside the papillary projection [19].

Color Doppler flow imaging evaluation of vessel distribution was performed in all cases to reduce the number of false positive findings in the diagnosis of endometrioma.

At enrollment a detailed medical, gynecologic and obstetric history was collected. Dysmenorrhea, dyspareunia and chronic pelvic pain were evaluated by a visual analogue scale (VAS) [20]. Intensity of symptoms was classified as none (0), mild (1-4), moderate (5-7), or severe (8-10). Fertility and pregnancy desire were assessed.

All patients underwent complete physical and gynecologic examination.

Ultrasound (US) with Color Doppler imaging evaluation was performed using a GE Medical Systems Voluson` 730 Expert Doppler ultrasound instrument (GE Healthcare, Waukesha, WI), equipped with 3D transabdominal $(3.5 \mathrm{MHz})$ and transvaginal $(5 \mathrm{MHz})$ probe for imaging and a pulsed Doppler system for blood flow analysis. Uterine arterial blood flow velocity waveforms were obtained by means of color flow imaging to identify ascending branch of the uterine artery on the left and right sides of the uterine isthmus. The 
sample volume was placed on the artery with an angle of about $0^{\circ}$. At least three consecutive, correctly imaged blood flow velocity waveforms were analyzed and the resistance index ( $\mathrm{RI}=$ maximal systolic velocity - least diastolic velocity / maximal systolic velocity) was calculated.

Resistance Index (RI) of uterine artery was evaluated during the mid-luteal phase $\left(20^{\text {th }}-22^{\text {nd }}\right.$ day of the cycle, confirmed by endometrial thickness between 8 and $16 \mathrm{~mm})$, by Transvaginal Doppler Ultrasound with color flow.

In the presence of clinical and US suspicion of adenomyosis or deep endometriosis, patients underwent 3D ultrasound (3D-US) and Magnetic Resonance Imaging (MRI). US and MRI signs of deep endometriosis consisted of the specific finding of posterior cul-de-sac (PCS) obliteration, as previously described [21,22]; uterosacral ligament (USL) involvement was suspected when increased and inhomogeneous thickness was associated with abnormal arciform appearance [23].

As shown by Kurjac et al. (1991) [24], under physiologic conditions uterine flow velocity has a RI of $0.88+/-0.04$ in the proliferative phase and starts to decrease the day before ovulation; a nadir of $0.84+/-0.04$ is reached on day 18 and the index remains at that level for the rest of the cycle. On the basis of Kurjac's findings, values of RI $<0.80$ were considered normal [24].

All patients with endometriomas $\geq 4 \mathrm{~cm}$ were scheduled for laparoscopic treatment according to current guidelines [25]. Laparoscopy was performed under general anesthesia.

At laparoscopy, the diagnosis of ovarian endometriosis was confirmed and the disease staged according to the revised classification of the American Society of Reproductive Medicine (rASRM) [2]. Excision by stripping of monolateral or bilateral endometriomas, adhesiolysis and excision, or coagulation of peritoneal lesions using bipolar forceps, were performed by the same surgeon (MGP) with more than 20 years of experience, according to a previously described technique [26].

Tubal patency was assessed by chromopertubation (Lap-Dye) in all patients. Histologic examination was also carried out in all cases.

Ultrasound examination with Doppler evaluation was performed at enrolment (T0) and 3 months after laparoscopy (T1) by two trained blinded physicians with 20 years of experience in pelvic ultrasound examinations. The median follow up was 7 (2-12) months.

All data obtained from both groups of patients were prospectively stored in an appropriate database.

Data were analyzed using the Statistical Package for Social Sciences (SPSS) version 18.

Parametric tests were carried out after having examined the normal distribution of data to be analyzed. The Student $t$ test was used for continuous parametric variables. The Fisher exact test and the chi-squared test were used for categorical variables. A P value below 0.05 was considered statistically significant.

\section{Results}

Among the 69 consecutive patients in whom a diagnosis of endometrioma was posed, only 42 met the inclusion criteria. In fact, 27 patients were excluded from the study: 16 were taking oral contraceptives, 3 presented also with uterine fibroids, 1 had uterine malformation, 2 had concomitant uterine adenomyosis and 5 had deep endometriosis nodules of the recto-vaginal septum confirmed by 3D-US and MRI.

Median age was 32 (range 20-45 years) in the group of patients with endometrioma and 30 (range 1845 years) in the control group $(\mathrm{P}=\mathrm{NS})$. No correlation was found between age and uterine artery RI values.

Characteristics of patients with endometriomas are reported in Table 1.

In 38 cases (90\%), unilateral or bilateral flow alterations $(R I \geq 0.8)$ were observed, whereas only 4 patients

\section{Table 1 Characteristic of patients with endometriosis at} T0

\begin{tabular}{lc}
\hline Characteristics & $\begin{array}{c}\text { Results } \\
\text { Median (range) }\end{array}$ \\
\hline Age & 32 (20-45) years \\
Endometriosis Symptoms & Patients (\%) \\
No dyspareunia & $28(67 \%)$ \\
Dyspareunia & \\
Grade I (1-4 VAS) & $4(9 \%)$ \\
Grade II (5-7 VAS) & $5(12 \%)$ \\
Grade III (8-10 VAS) & $5(12 \%)$ \\
No dysmenorrhea & $13(31 \%)$ \\
Dysmenorrhea & \\
Grade I (1-4 VAS) & $2(5 \%)$ \\
$\quad$ Grade II (5-7 VAS) & $10(24 \%)$ \\
$\quad$ Grade III (8-10 VAS) & $17(40 \%)$ \\
No Chronic pelvic pain (CPP) & $35(83 \%)$ \\
CPP $\quad$ Grade I (1-4 VAS) & \\
Grade II (5-7 VAS) & $12(29 \%)$ \\
Grade III (8-10 VAS) & 0 \\
Onknown (with no desire of pregnancy & $6(14 \%)$ \\
Fertile & $1(2 \%)$ \\
\hline
\end{tabular}


showed a normal bilateral RI value. Among the 38 patients with Doppler alterations, 25 (66\%) had bilateral and 13 (34\%) unilateral increased RI values. The unilateral RI alteration coincided with the presence of homolateral endometrioma (Figure 1). All cases with infertility (primary in 17 cases and secondary in 2 cases) presented uterine artery flow alteration at T0.

In the control group, 17 subjects (41\%) had Doppler alterations, whereas 24 (58\%) had no abnormalities. Among the 17 women with Doppler alterations, 14 (82\%) presented unilateral and only $3(18 \%)$ bilateral high RI values.

A statistically significant difference between the median RI value in patients with endometrioma (0.84; range $0.6-1$ ) and in the control group (0.76; range 0.48-0.97) was found $(\mathrm{p}<0.001)$.
Bilateral uterine artery blood flow alterations were significantly more frequent in the group of patients with endometrioma than in controls $(\mathrm{p}=0.001)$.

Case-control comparison data are reported in Table 2.

At surgery, the presence of ovarian endometriosis was confirmed in all women; median size of the cyst was $43 \mathrm{~mm}$ (range 19-97 $\mathrm{mm}$ ) in the right ovary and $38 \mathrm{~mm}$ (range $20-110 \mathrm{~mm}$ ) in the left ovary, the overall median size was $40 \mathrm{~mm}$ (range $19-110 \mathrm{~mm}$ ). All patients had at least 1 ovarian endometrioma $\geq 40 \mathrm{~mm}$.

Bilateral ovarian endometriomas were found in 21 cases (50\%), unilateral cysts in the remaining $21 ; 8$ (38\%) in the right ovary and 13 (62\%) in the left ovary.

Adnexal adhesions were found in 28 cases (67\%): adhesiolysis was performed in all patients. According to the rASRM classification, 18 women (43\%) had stage III
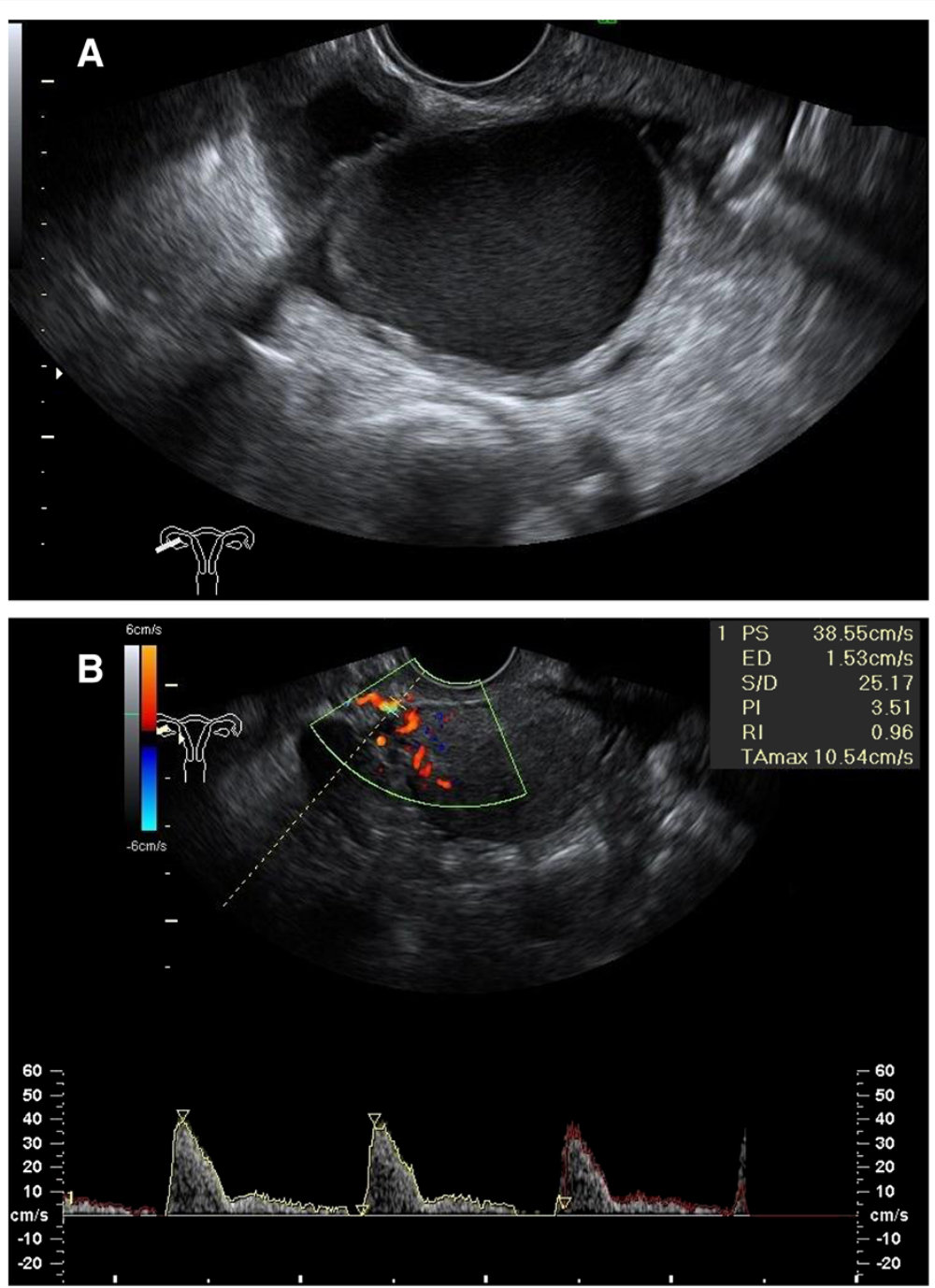

Figure 1 Transvaginal ultrasonography and color Doppler. (A) Right ovarian endometrioma and (B) Homolateral pre-operative Doppler flow alteration $(\mathrm{RI}=0.96)$. 
Table 2 Ultrasonographic Doppler RI values (case-control comparison)

\begin{tabular}{cccc}
\hline Characteristics & \multicolumn{3}{c}{ Results } \\
\cline { 2 - 3 } & \multicolumn{2}{c}{ Median (range) } & P value \\
\cline { 2 - 3 } & Case & Control & \\
\hline Median Rl value & $0.84(0.6-1)$ & $0.76(0.48-0.97)$ & $<0.001$ \\
\hline & \multicolumn{2}{c}{ Patients (\%) } & \\
\cline { 2 - 3 } & Case & Control & \\
\hline $\mathrm{Rl} \geq 0.8$ & $38(90 \%)$ & $17(41 \%)$ & $<0.001$ \\
$\mathrm{Rl}<0.8$ & $4(10 \%)$ & $24(59 \%)$ & \\
Unilateral Rl alteration & $13(34 \%)$ & $14(82 \%)$ & 0.001 \\
Bilateral Rl alteration & $25(66 \%)$ & $3(18 \%)$ & \\
\hline
\end{tabular}

endometriosis and 24 (57\%) had stage IV. No cases were classified as early stages of disease (I or II). No statistically significant correlation was found between rASRM stages III and IV and RI flow alterations $(\mathrm{p}=\mathrm{NS})$.

At chromopertubation (Lap-Dye) 15 (36\%) patients had bilateral tubal patency, whereas $12(28 \%)$ presented unilateral distal tubal occlusion (DTO), 10 (24\%) unilateral proximal tubal occlusion (PTO) and $5(12 \%)$ bilateral tubal occlusion (PTO in 1 patient and DTO in 4 women). Salpingoplasty was performed achieving tubal patency in 7 patients. No correlation was found between tubal status and uterine artery RI.

In all cases, histopathologic examination confirmed the diagnosis of endometrioma.

Among women with bilateral endometriomas, 14 (67\%) had bilateral high RI values, whereas 5 (24\%) had unilateral flow alterations and only $2(9 \%)$ had no abnormalities.

Among patients with unilateral endometrioma 18 (85\%) had homolateral flow alteration, only $1(5 \%)$ had contralateral RI alteration and $2(10 \%)$ had normal uterine artery flow.

Surgical findings in patients with endometrioma and their possible correlation with Doppler flow alterations are reported in Table 3.

No surgical findings were significantly correlated to Doppler flow values. Moreover, no statistically significant correlation was found between RI values and pain symptom intensity (dysmenorrhea, dyspareunia and chronic pelvic pain) evaluated by VAS score system $(\mathrm{p}=\mathrm{NS})$.

Three months after surgery (T1), 23 (55\%) patients had normal RI values (Figure 2), whereas 6 (14\%) had bilateral and 13 (31\%) unilateral flow alterations. In 19 out of 42 patients (45\%) uterine RI artery flow persisted altered, even if in 7 cases a RI improvement was observed, although with values above normal.

There was a statistically significant difference between the number of patients with RI alterations at T0 (90\%) and the number of patients with RI alterations at T1 $(45 \%)(\mathrm{p}<0.001)$ : these results are reported in Table 4.
Table 3 Surgical findings in patients with endometriosis and Doppler flow alterations (RI)

\begin{tabular}{lcc}
\hline Surgical findings & Results & $\begin{array}{c}\mathrm{P} \\
\text { value }\end{array}$ \\
\hline Cyst & &
\end{tabular}

Cyst

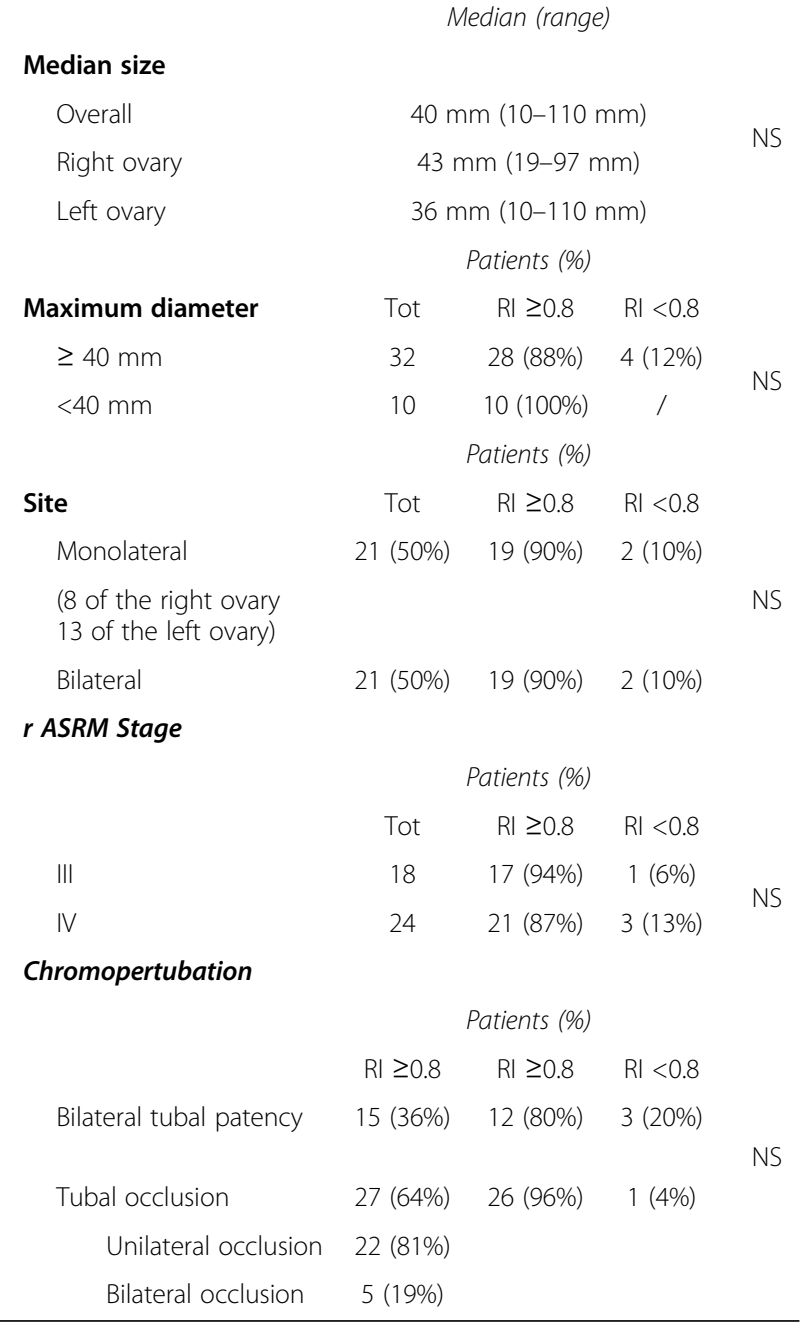

Even if it was not the main objective of our study, we evaluated the reproductive outcome in terms of number of pregnancies during the limited follow-up period of a median of 7 months. Twenty-four patients (57\%) desired pregnancy before surgery. Nineteen of them (79. 2\%) were infertile (17 with primary and 2 with secondary infertility), and they all showed uterine artery Doppler alterations before surgery. Three months after laparoscopy, 14 (73.7\%) out of 19 infertile patients had normal uterine artery RI flow, whereas RI alterations persisted in 5 cases.

Twelve out of the 19 (63\%) infertile patients achieved a spontaneous pregnancy during the follow-up and all of them had normal RI values after surgery. Eight 


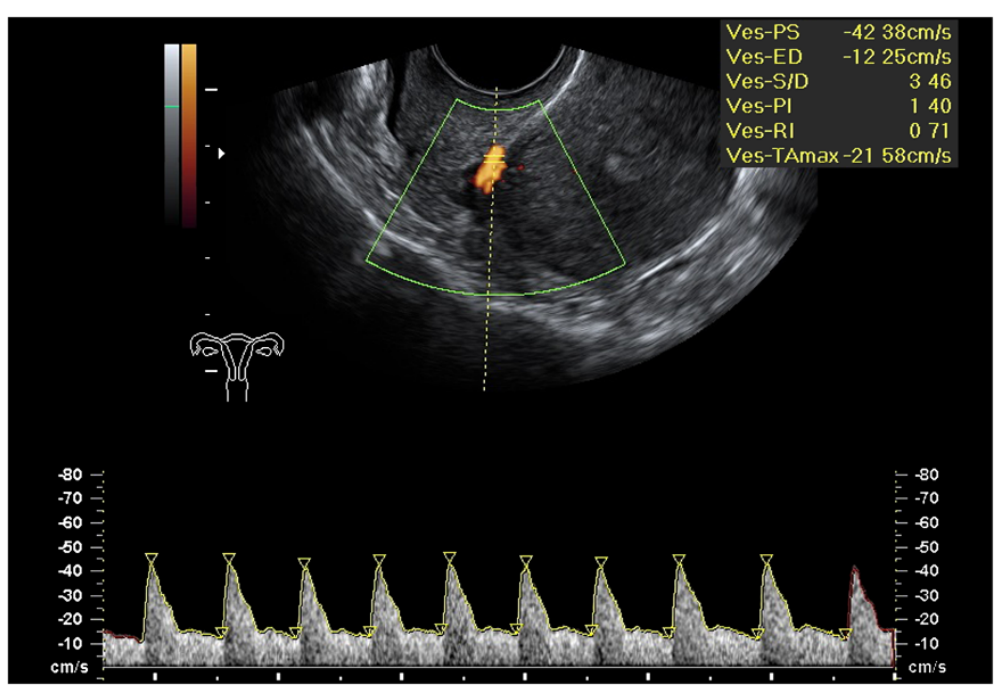

Figure 2 Normalization of right uterine artery resistance index after laparoscopy $(\mathrm{RI}=\mathbf{0 . 7 1 )}$ (the figure referred to the same patient reported in Figure 1).

pregnancies (67\%) occurred within the first 6 months and $4(33 \%)$ within one year from laparoscopy. Five (41\%) spontaneous pregnancies occurred in women showing a slow tubal passage of dye during laparoscopy; in 2 cases with a distal tubal obstruction a salpingoplasty was performed restoring tubal patency. The patient with bilateral proximal tubal occlusion underwent IVF-ET assisted reproductive technique with unfavorable fertility outcome.

A statistically significant difference in term of pregnancy rate was found between patients with normal RI values and those with persistent uterine artery flow alterations after surgery $(p=0.002)$. Pregnancy outcome is reported in Table 5.

Among the remaining 18 patients with no desire for pregnancy, 10 received hormonal contraception after surgery.

\section{Discussion}

In the present study we observed that uterine artery RI was significantly altered in patients with ovarian endometriomas ( $R I$ value $\geq 0.8$ ), showing higher uterine artery flow resistance compared with unaffected controls. In particular, all infertile patients presented uterine artery flow alteration at $\mathrm{T} 0$, confirming the possible role of uterine artery abnormalities in endometriosis-associated infertility.

Table 4 Post-operative Doppler modifications of uterine artery resistance index $\mathbf{R I}$

\begin{tabular}{llll}
\hline & \multicolumn{2}{c}{ Patients (\%) } & P value \\
\cline { 2 - 3 } & $\mathbf{R I} \geq \mathbf{0 . 8}$ & $\mathbf{R I}<\mathbf{0 . 8}$ & \\
\hline Pre-operative & $38(90 \%)$ & $4(10 \%)$ & $<0.001$ \\
Post-operative & $19(45 \%)$ & $23(55 \%)$ & \\
\hline
\end{tabular}

Moreover, we observed that after laparoscopic treatment of the ovarian endometriomas, RI values returned to normal in the majority of patients. Uterine artery flow improvement was associated to a better fertility outcome with a percentage of spontaneous pregnancies of 67\%; this rate is similar to post-operative pregnancy rate reported in the literature $[27,28]$.

At present, surgical management of endometriomas in infertile women is the subject of debate, although there seems to be a growing consensus that these cysts should not be systematically removed.

Disagreement on the best treatment is predicated upon a series of conflicting findings. On the one hand, there is consistent evidence indicating that ovarian reserve is affected following surgical excision of ovarian endometriomas [29-32]. On the other, in infertile patients subjected to IVF without cyst excision, there is a risk of developing ovarian abscess following egg retrieval, due to contamination of the cyst content, as well as of rupture of the endometrioma. In addition, there may be difficulties in follicle aspiration, the risk of misdiagnosing

Table 5 Pregnancy rate after surgery

\begin{tabular}{lll}
\hline & Patients (\%) & P-value \\
\hline Overall pregnancy rate & $12 / 42(37 \%)$ & \\
Pregnancy rate in & $12 / 19(63 \%)$ & \\
infertile patients & &
\end{tabular}

Pregnancies No Pregnancies

Pregnancy rate according to post-operative Doppler values in infertile patients

\begin{tabular}{lccc}
$\mathrm{Rl} \geq 0.8$ & 0 & $5(100 \%)$ & \\
$\mathrm{Rl}<0.8$ & $12(86 \%)$ & $2(14 \%)$ & 0.002 \\
\hline
\end{tabular}


an ovarian cancer and a growth of the cyst during pregnancy with a detrimental impact on its outcome [29,33-35].

Nevertheless data suggest that laparoscopic surgery is effective in the treatment of infertility associated with moderate to severe endometriosis, as long as resection is carefully carried out, avoiding substantial reduction of the ovarian reserve. Under these circumstances, excision of the cyst is associated with a subsequent increase in spontaneous pregnancy rate if compared with ablation [28,36-38].

Patients with endometriosis have been identified as having a variety of endocrine alterations that may impair the reproductive process and an altered uterine artery flow may be one. In these patients, luteal phase defects may be linked to decreased vascularization of the corpus luteum, due to the presence of the endometriotic cyst, with a consequent inadequate progesterone production; as such, it can be detected by studying ovarian and uterine artery flow dynamics. As previously mentioned, a recent paper published by El-Mazny et al. [18] highlighted that endometrial perfusion may play a role in the pathogenesis of infertility. The authors observed significantly more altered uterine artery flows in patients with unexplained infertility than in fertile parous controls. Moreover, since there were no significant differences in endometrial thickness and volume between the two groups, they hypothesized that the reduction in endometrial perfusion in the infertile group is more likely to reflect an aberrant end-organ effect of ovarian hormones on endometrial blood vessels. This may be due to suboptimal endometrial angiogenesis or dynamic vascular changes such as vasoconstriction or reduced vasodilatation [39].

Endometriosis is also associated with functional and structural changes in the eutopic endometrium and inner myometrium. The fact that we observed a strong correlation between uterine artery flow alteration and the presence of ovarian endometriosis supports the hypothesis that a defective blood supply may intervene in the overall mechanism of endometriosis-induced infertility, especially because this situation seems modifiable through surgical treatment. It is possible that the distortion of pelvic anatomy caused by the presence of endometriomas and/or the related inflammation could be responsible for uterine artery flow abnormalities which can be restored by surgical treatment. It is also possible that in the presence of an endometrioma associated to alterations in uterine artery blood flow, there are arteriosclerotic lesions in the endometrioma bed as suggested by Maneschi et al. [40] and/or endothelial dysfunction as suggested by Santoro et al. [40,41]. The present study has some limitations, first and foremost the relatively small number of cases and the short follow-up, even if most of the pregnancies after surgery for endometrioma usually occur within the first 6 months. Evaluation of reproductive outcome is still ongoing since a number of patients have not completed 1 year follow-up.

\section{Conclusions}

Our results suggest that a careful evaluation of uterine artery flow may assume a role as prognostic factor of reproductive outcome after surgical treatment of ovarian endometrioma. Further studies are ongoing to confirm these preliminary data.

\section{Abbreviations}

RI: Resistance index; IVF: in vitro fertilization; ET: Embryo transfer; US: Ultrasound; VAS: Visual analogue scale; MRI: Magnetic Resonance Imaging; PCS: Posterior Cul-de-sac; USL: Uterosacral ligament; rASRM: Revised classification of American Society of Reproductive Medicine; NS: Not significant; DTO: Distal tubal occlusion; PTO: Proximal tubal occlusion.

\section{Competing interests}

All authors declare that they have no competing interest.

\section{Authors' contributions}

MGP, MGPi and PBP conceived the study and participated in its design. MGPi and LM performed the ultrasound examinations. MGP, FT, DY, EF and $\mathrm{GB}$ participated in the analysis and interpretation of data. DY, FT and EF collected the data. MGP, MGPi, GB, DY, FT, LM, PBP and EF wrote the paper. All authors read and approved the final manuscript.

\section{Author details}

${ }^{1}$ Department of Gynecology, Obstetrics and Urology, Sapienza, University of Rome, Policlinico Umberto I, Viale Regina Elena 324, Rome 00161, Italy. ${ }^{2}$ Department of Radiological Sciences, Oncology and Pathology, Sapienza, University of Rome, Policlinico Umberto I, Viale Regina Elena 324, Rome 00161, Italy.

Received: 21 October 2013 Accepted: 13 December 2013

Published: 8 January 2014

\section{References}

1. Petraglia F, Arcuri F, de Ziegler D, Chapron C: Inflammation: a link between endometriosis and preterm birth. Fertil Steril 2012, 98(1):36-40.

2. Practice Committee of the American Society for Reproductive Medicine: Endometriosis and infertility: a committee opinion. Fertil Steril 2012, 98(3):591-598.

3. Rogers PA, D'Hooghe TM, Fazleabas A, Giudice LC, Montgomery GW, Petraglia F, Taylor RN: Defining future directions for endometriosis research: workshop report from the 2011 World Congress of Endometriosis In Montpellier, France. Reprod Sci 2013, 20(5):483-499.

4. de Ziegler D, Borghese B, Chapron C: Endometriosis and infertility: pathophysiology and management. Lancet 2010, 376(9742):730-738.

5. Macer ML, Taylor HS: Endometriosis and infertility: a review of the pathogenesis and treatment of endometriosis-associated infertility. Obstet Gynecol Clin N Am 2012, 39(4):535-549.

6. Carvalho LFP, Rossener R, Azeem A, Malvezzi H, Simões Abrão M, Agarwal A: From conception to birth: how endometriosis affects the development of each stage of reproductive life. Minerva Ginecol 2013, 65(2):181-198.

7. Brosens I, Gordts S, Benagiano G: Endometriosis in adolescents is a hidden, progressive and severe disease that deserves attention, not just compassion. Hum Reprod 2013, 28(8):2026-2031.

8. Loh FH, Tan AT, Kumar J, Ng SC: Ovarian response after laparoscopic ovarian cystectomy for endometriotic cysts in 132 monitored cycles. Fertil Steril 1999, 72(2):316-321.

9. Horikawa T, Nakagawa K, Ohgi S, Kojima R, Nakashima A, Ito M, et al: The frequency of ovulation from the affected ovary decreases following laparoscopic cystectomy in infertile women with unilateral endometrioma during a natural cycle. J Assist Reprod Genet 2008, 25(6):239-244 
10. Shah DK: Diminished ovarian reserve and endometriosis: insult upon injury. Semin Reprod Med 2013, 31(2):144-149.

11. Tinkanen $\mathrm{H}$, Kujansuu $\mathrm{E}$ : In vitro fertilization in patients with ovarian endometriomas. Acta Obstet Gynecol Scand 2000, 79(2):119-122.

12. Donnez J, Wyns C, Nisolle M: Does ovarian surgery for endometriomas impair the ovarian response to gonadotropin? Fertil Steril 2001 , 76(4):662-665.

13. Opøien HK, Fedorcsak P, Omland AK, Abyholm T, Bjercke S, Ertzeid G, Oldereid N, Mellembakken JR, Tanbo T: In vitro fertilization is a successful treatment in endometriosis-associated infertility. Fertil Steril 2012, 97(4):912-918

14. Demirol A, Guven S, Baykal C, Gurgan T: Effect of endometrioma cystectomy on IVF outcome: a prospective randomized study. Reprod Biomed Online 2006, 12(5):639-643.

15. Steer CV, Campbell S, Pampiglione JS, Kingsland CR, Mason BA, Collins WP: Transvaginal color flow imaging of the uterine arteries during the ovarian and menstrual cycles. Hum Reprod 1990, 5(4):391-395.

16. Steer CV, Tan SL, Mason BA, Campbell S: Midluteal-phase vaginal color Doppler assessment of uterine artery impedance in a subfertile population. Fertil Steril 1994, 61(1):53-58.

17. Exacoustos C, Brienza L, Di Giovanni A, Szabolcs B, Romanini ME, Zupi E, et al: Adenomyosis: three-dimensional sonographic findings of the junctional zone and correlation with histology. Ultrasound Obstet Gynecol 2011, 37(4):471-479.

18. El-Mazny A, Abou-Salem N, Elshenoufy H: Doppler study of uterine hemodynamics in women with unexplained infertility. Eur J Obstet Gynecol Reprod Biol. in press.

19. Guerriero S, Ajossa S, Mais V, Risalvato A, Lai MP, Melis GB: The diagnosis of endometriomas using color Doppler energy imaging. Hum Reprod 1998, 13(6):1691-1695.

20. Joyce CR, Zutshi DW, Hrubes V, Mason RM: Comparison of fixed interval and visual analogue scales for rating chronic pain. Eur J Clin Pharmacol 1975, 8(6):415-420

21. Manganaro L, Fierro F, Tomei $A$, Irimia D, Lodise $P$, Sergi ME, et al: Feasibility of 3.0T pelvic MR imaging in the evaluation of endometriosis. Eur J Radiol 2012, 81(6):1381-1387.

22. Manganaro L, Vittori G, Vinci V, Fierro F, Tomei A, Lodise $P$, Sollazzo $P$, et al: Beyond laparoscopy: 3-T magnetic resonance imaging in the evaluation of posterior cul-de-sac obliteration. Magn Reson Imaging 2012, 30(10):1432-1438

23. Manganaro L, Vinci V, Bernardo S, Storelli P, Fuggetta E, Sollazzo P, et al: The role of 3.0T MRI in the assessment of deep endometriosis located on the uterosacral ligaments. J Endom 2013, 5(1):10-16.

24. Kurjak A, Kupesic-Urek S, Schulman H, Zalud I: Transvaginal color flow Doppler in the assessment of ovarian and uterine blood flow in infertile women. Fertil Steril 1991, 56(5):870-873

25. Kennedy S, Bergqvist A, Chapron C, D'Hooghe T, Dunselman G, Greb R, Hummelshoj L, Prentice A, Saridogan E, ESHRE Special Interest Group for Endometriosis and Endometrium Guideline Development Group: ESHRE guideline for the diagnosis and treatment of endometriosis. Hum Reprod 2005, 20(10):2698-2704.

26. Porpora MG, Pallante D, Ferro A, Crisafi B, Bellati F, Benedetti Panici P: Pain and ovarian endometrioma recurrence after laparoscopic treatment of endometriosis: a long-term prospective study. Fertil Steril 2010, 93(3):716-721.

27. Osuga $Y$, Koga K, Tsutsumi O, Yano T, Maruyama M, Kugu K, Momoeda M, Taketani Y: Role of laparoscopy in the treatment of endometriosisassociated infertility. Gynecol Obstet Invest 2002, 53(Suppl 1):33-39.

28. Porpora MG, Pultrone DC, Bellavia M, Franco C, Crobu M, Cosmi EV: Reproductive outcome after laparoscopic treatment of endometriosis. Clin Exp Obstet Gynecol 2002, 29(4):271-273.

29. Garcia-Velasco JA, Somigliana E: Management of endometriomas in women requiring IVF: to touch or not to touch. Hum Reprod 2009, 24(3):496-501

30. Benaglia L, Somigliana E, Vighi V, Ragni G, Vercellini P, Fedele L: Rate of severe ovarian damage following surgery for endometriomas. Hum Reprod 2010, 25(3):678-682.

31. Benaglia $L$, Pasin $R$, Somigliana $E$, Vercellini $P$, Ragni $G$, Fedele $L$ : Unoperated ovarian endometriomas and responsiveness to hyperstimulation. Hum Reprod 2011, 26(6):1356-1361.
32. Almog B, Shehata F, Sheizaf B, Tan SL, Tulandi T: Effects of ovarian endometrioma on the number of oocytes retrieved for in vitro fertilization. Fertil Steril 2011, 95(2):525-527.

33. Somigliana E, Vercellini $P$, Viganó $P$, Ragni G, Crosignani PG: Should endometriomas be treated before IVF-ICSI cycles? Hum Reprod Update 2006, 12(1):57-64.

34. Benaglia L, Somigliana E, lemmello R, Colpi E, Nicolosi AE, Ragni G: Endometrioma and oocyte retrieval-induced pelvic abscess: a clinical concern or an exceptional complication? Fertil Steril 2008, 89(5):1263-1266.

35. Benaglia L, Somigliana E, Vighi V, Nicolosi AE, lemmello R, Ragni G: Is the dimension of ovarian endometriomas significantly modified by IVF-ICSI cycles? Reprod Biomed Online 2009, 18(3):401-406.

36. Nezhat C, Winer WK, Cooper JD, Nezhat F, Nezhat C: Endoscopic infertility surgery. J Reprod Med 1989, 34(2):127-134.

37. Vercellini P, Fedele L, Aimi G, De Giorgi O, Consonni D, Crosignani PG: Reproductive performance, pain recurrence and disease relapse after conservative surgical treatment for endometriosis: the predictive value of the current classification system. Hum Reprod 2006, 21(10):2679-2685.

38. Hart RJ, Hickey M, Maouris P, Buckett W, Garry R: Excisional surgery versus ablative surgery for ovarian endometriomata. Cochrane Database Syst Rev 2008, 2, CD004992.

39. Raine-Fenning NJ, Campbell BK, Kendall NR, Clewes JS, Johnson IR: Endometrial and subendometrial perfusion are impaired in women with unexplained subfertility. Hum Reprod 2004, 19:2605-2614.

40. Maneschi F, Marasá L, Incandela S, Mazzarese M, Zupi E: Ovarian cortex surrounding benign neoplasms: a histologic study. Am J Obstet Gynecol 1993, 169(2 Pt 1):388-393.

41. Santoro L, D'Onofrio F, Campo S, Ferraro PM, Tondi P, Campo V, Flex A, Gasbarrini A, Santoliquido A: Endothelial dysfunction but not increased carotid intima-media thickness in young European women with endometriosis. Hum Reprod 2012, 27(5):1320-1326.

doi:10.1186/1757-2215-7-1

Cite this article as: Porpora et al.: Impaired uterine artery flow associated with the presence of ovarian endometrioma: preliminary results of a prospective study. Journal of Ovarian Research 2014 7:1.

\section{Submit your next manuscript to BioMed Central and take full advantage of:}

- Convenient online submission

- Thorough peer review

- No space constraints or color figure charges

- Immediate publication on acceptance

- Inclusion in PubMed, CAS, Scopus and Google Scholar

- Research which is freely available for redistribution 